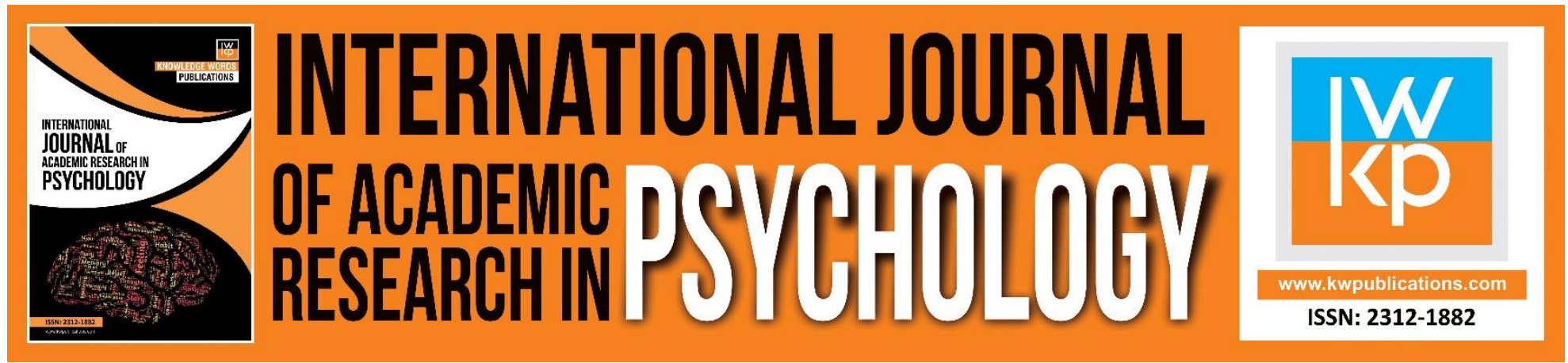

\title{
Parental Experiences with Duchenne Muscular Dystrophy: Feelings of loss and Empowerment
}

Ioanna Koufaki, Katerina Kedraka, Ioanna lerodiakonou-Benou, Maria Samakouri

To Link this Article: http://dx.doi.org/10.46886/IJARP/v6-i1/6393

DOI:10.46886/IJARP/v6-i1/6393

Received: 09 March 2019, Revised: 13 April 2019, Accepted: 10 May 2019

Published Online: 28 May 2019

In-Text Citation: (Koufaki et al., 2019)

To Cite this Article: Koufaki, I., Kedraka, K., lerodiakonou-Benou, I., \& Samakouri, M. (2019). Parental Experiences with Duchenne Muscular Dystrophy: Feelings of loss and Empowerment. International Journal of Academic Research in Psychology, 6(1), 16-29.

Copyright: (C) 2019 The Author(s)

Published by Knowledge Words Publications (www.kwpublications.com)

This article is published under the Creative Commons Attribution (CC BY 4.0) license. Anyone may reproduce, distribute, translate and create derivative works of this article (for both commercial and non-commercial purposes), subject to full attribution to the original publication and authors. The full terms of this license may be seen

at: http://creativecommons.org/licences/by/4.0/legalcode

Vol. 6, No. 1, 2019, Pg. 16 - 29

https://kwpublications.com/journals/journaldetail/IJARP

JOURNAL HOMEPAGE

Full Terms \& Conditions of access and use can be found at https://kwpublications.com/pages/detail/publication-ethics 


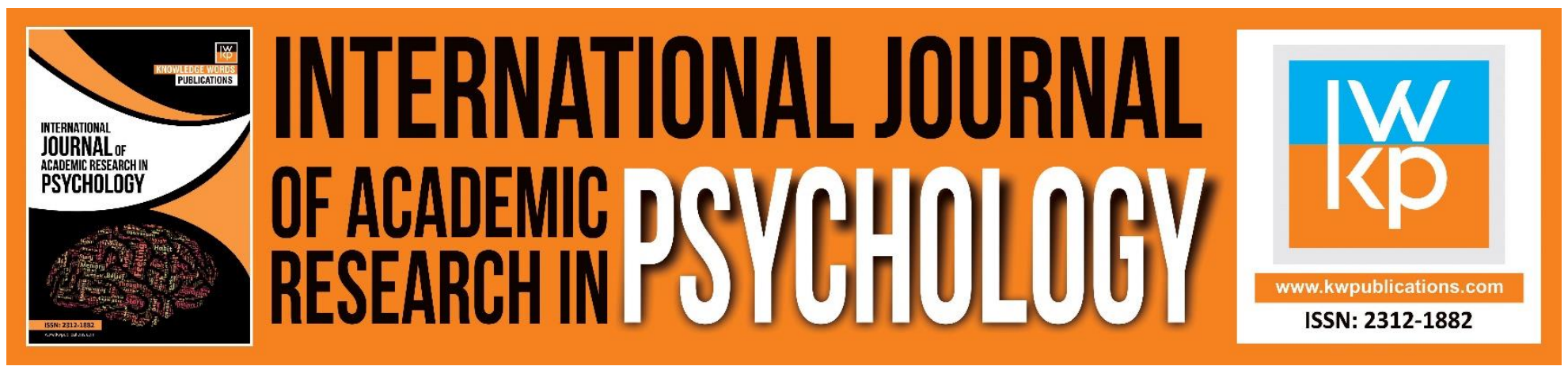

\title{
Parental Experiences with Duchenne Muscular Dystrophy: Feelings of loss and empowerment
}

\author{
loanna Koufakia , Katerina Kedraka ${ }^{\mathrm{b}}$, loanna lerodiakonou-Benouc, \\ Maria Samakouri ${ }^{d}$ \\ ${ }^{a}$ Clinical Psychologist, Democritus University of Thrace, University Psychiatric Department, Dragana, \\ 68100, Alexandroupolis, Greece, ${ }^{\mathrm{b}}$ Associate Professor of Teaching and Job Skills of Bioscientists, \\ Department of Molecular Biology \& Genetics, Democritus University of Thrace, Dragana, \\ Alexandroupolis, 68100, Greece, 'Associate Professor of Psychiatry, Aristotle University of \\ Thessaloniki, University Psychiatric Department, University Campus, 54124, Thessaloniki, Greece, \\ dProfessor of Psychiatry, Democritus University of Thrace, University Psychiatric Department, \\ Dragana, Alexandroupolis, 68100, Greece.
}

Email: ikoufaki@hotmail.com, kkedraka@mbg.duth.gr, impenou@auth.gr, msamakou@med.duth.gr

\begin{abstract}
Muscular dystrophies are a heterogeneous group of mainly hereditary diseases that affect the functioning of the muscle system. Few studies have focused on the psychological adjustment of parents of children with Duchenne muscular dystrophy. This study's objective was to investigate the parents' experience and the process of adjustment to the complex nature of their child's disorder. The study used a qualitative research design. Qualitative thematic analysis was used to analyze the data collected from parents $(n=9)$ of children with Duchenne muscular dystrophy $(n=10)$ using the technique of semi-structured interviews. The parents' experience is characterized by painful and recurrent losses, which intensify their feelings of isolation and parental responsibility. On the other hand, parents develop internal coping mechanisms and identify sources of empowerment, which they evaluate as positive aspects of their experience. Recurrent losses alternate with periods of stability, hope and efforts toward normalcy in family life. Results of this study implicate the importance of adequate psychosocial interventions that will allow parents to cope with complex challenges, elaborate on their experiences and identify internal and external resources.
\end{abstract}

Keywords: Duchenne Muscular Dystrophy, Psychological Adjustment, Parents, Children.

\section{Introduction}

\section{Duchenne Muscular Dystrophy}

Muscular dystrophies are a heterogeneous group of diseases, with symptoms including muscle weakness that affect mobility. The majority of muscular dystrophies are hereditary and caused by 
INTERNATIONAL JOURNAL OF ACADEMIC RESEARCH IN PSYCHOLOGY

Vol. 6, No. 1, 2019, E-ISSN:2312-1882@ 2019 HRMARS

DNA mutations that are commonly inherited either by one or both parents (Andersson \& Rando, 1999).

Duchenne muscular dystrophy (DMD) is among the most common muscular dystrophies of childhood with prevalence at 1:3500 male births regardless of race or ethnic origin (Emery, 1998). It is a degenerative disease, inherited as an X-linked recessive genetic disorder caused by a mutation or lack of the protein dystrophin. It causes progressive weakness by affecting all body muscles and leads to early death (Emery, 2002). Although the specific gene mutation may occur in the family, about $1 / 3$ of DMD cases may result from spontaneous mutations (Emery, 1998).

Given the absence of therapy for the disease, the existing therapeutic interventions focus on the amelioration of the patients' quality of life. Life expectancy of patients with Duchenne Muscular Dystrophy has increased compared to the previous decades (Emery, 2002). Patients' survival age reaches $25-30$ years old, with the development of medical care and the use of respiratory support (Emery, 2002).

\section{Parental Experiences of Psychological Adjustment to the Illness}

The overall experience of parenting a child with neuromuscular disease has only been explored by a small group of studies. Parental experience has previously been described by a range of emotional states-from mourning to illness acceptance and hope (Bregman, 1980; Gagliardi, 1991b). However, the grief process in DMD may be more efficiently explained by the chronic sorrow model (Eakes, Burke, \& Hainsworth, 1998). Instead of reaching a final acceptance of loss and some form of grief resolution, the person will re-experience grief reactions every time the disorder deteriorates. DMD is characterized by recurrent losses and the appearance of new symptoms may trigger emotional reactions of sorrow and despair similar to those at the initial stages of diagnosis. Periods of calmness and satisfaction will be disrupted by phases of grief processing (Poysky \& Kinnett, 2009; Saetrang et al., 2019).

The main theme in Gravelle's study (1997) was "facing adversity" and included the constant challenges that parents face as a result of their child's progressive disorder. Gagliardi (1991a) pointed out that family members gradually develop strategies for coping with stress in order to maintain family balance. More recent research showed that hope emerges by the confirmation that the child is able to enjoy every day life as a result of parental caretaking (Samson et al., 2009). In a study by Carnevale, Alexander, Davis, Rennick and Troini (2006) the majority of the families described their life experiences with the disorder as overly unfair and impossible to change.

Cipolletta Marchesin and Benini (2015) investigated the ways that family function may affect the clinical course of the disorder. Four different ways of processing the disorder were shown, each one corresponding to different family systems: (1) Possibility: acceptance of the disorder and autonomy of the children, (2) Focus on the disorder and emergence of a "symbiotic bonding" between the mother and the child, (3) Denial of the disorder, minimization of the diagnosis and aggravation of the disorder and, (4) Anger and a strong sense of responsibility.

Parental responsibility has been associated with high levels of stress and emotional exhaustion (Boström, Ahlström, \& Sunvisson, 2006; Carnevale et al., 2006; Moraiti, 2011). Constant caretaking may affect family relationships by increasing emotional and physical dependency, therefore complicating the issues of child autonomy (Boström et al., 2006; Boyer, Drame, Morrone, \& Novella, 2006; Metcalfe et al., 2008).

Coping with DMD can be overwhelming and parents employ different strategies to face emotional and practical challenges. In sum, parents make short term plans, take each day as it comes (Bregman, 
1980; Erby, Rushton, \& Geller, 2006; Webb, 2005) and compartmentalize time according to crucial transitional stages of the disorder (Roy, 2008). Normal functioning and consistency of the family, religious beliefs and satisfaction of the parents' personal needs have also been indicated as sources of empowerment (Abi Daoud, Dooley, \& Gordon, 2004). Strong bonding among family members (Magliano et al., 2014) and maintenance of supportive networks have been proposed as factors that determine family adjustment (Abi Daoud et al., 2004; Gagliardi, 1991a; Nereo, Fee, \& Hinton, 2003) and improve quality of life (Hatzmann et al., 2009). Many families concentrate on everyday activities that allow a sense of normalcy in family function (Dawson \& Kristjanson, 2003; Tomiak et al., 2007). Through a sense of normalcy, caretaking demands may not trigger additional stress (Chen \& Clark, 2007), guilt and ambivalent feelings towards the child (Moraiti, 2011).

The crucial role of health care teams was described in a study by Bendixen \& Houtrow (2017). Parents felt empowered by good doctor parent relationship that resulted in higher quality healthcare for the child and better adaptation to their role. Resilience in caring for someone with DMD was found to be influenced by personal coping strategies, social support and the ability to develop perseverance in order to handle caring demands (Glover et al., 2018). A study by Peay et al (2016) indicated that although mothers experienced higher caregiver burden as their child's disorder progressed, they were still able to recognize major positive changes associated with their life experiences with Duchenne and Becker muscular dystrophy.

Muscular Dystrophies are rare diseases and only few studies have focused on the emotional experience of parents of children diagnosed with DMD (Glover et al., 2018).An overview of studies on neuromuscular disorders confirms either a domination of a biomedical approach to the subject, or a quantitative exploration of mainly social variables (LaDonna, 2011). Also, the particular characteristics of DMD, which is a rapidly progressive terminal disorder, render the experience of parents unique as compared to other types of disorders and/or disabilities. We therefore sought to contribute to previous research and to further investigate the subject towards an in-depth understanding of the parents' experience.

\section{Methods}

\section{Aim of the Study}

The aim of this study is to further broaden current knowledge on the experience of parents of children with DMD diagnosis. In particular, the parents' psychological adaptation to the chronic disorder of their children will be explored, along with its impact on them and the ways they deal with difficulties related to the disorder. Understanding the parents' experiences is expected to contribute to the improvement of psychosocial support following diagnosis.

\section{Study Design}

A qualitative research approach is used, as it allows an in-depth understanding of human experience, as well as an analytical exploration of the special circumstances within which human behavior emerges (Kedraka, 2013). The study intends to analyze in depth, through thematic analysis, the discourse of 10 parents of children with DMD. It was considered the most appropriate, because it allows an in-depth analysis and interpretation of the data, allowing the participants the greatest possible freedom to reveal what they consider important, the "truth" they want to report (Patton, 2015). Qualitative research interview has the essential flexibility to capture subtle shades of meaning of the subjects' experience (Berg, 2001)-the experience of parents of children with a chronic disorder. 
INTERNATIONAL JOURNAL OF ACADEMIC RESEARCH IN PSYCHOLOGY

Vol. 6, No. 1, 2019, E-ISSN:2312-1882@ 2019 HRMARS

Data collection followed the technique of semi-structured interviews. An interview guide was developed:

- What were your initial reactions when you were informed about your child's diagnosis?

- Have you experienced any personal changes, or changes with regard to parenting your children throughout this period? Are there any changes in the way you face others and approach life in general?

- What are your personal coping resources? Drawing on your experience what advice would you give to parents who have just been informed that their child has received a similar diagnosis? Questions were adjusted to the verbiage of the respondents, who were free to talk aboutissues that diverged from the initial interview guide. The order of questions might vary and additional questions were asked throughout the interview process in order to clarify ambiguities. Interviews were recorded with the respondents' consent, in order to ensure a precise capture of content.

\section{Participants}

Purposeful sampling was used to recruit parents of children with DMD diagnosis, who attended a specialized University outpatient clinic in Northern Greece. Purposeful sampling strategies are widely used in qualitative research to select information-rich cases that will allow an in-depth exploration of the subject under investigation (Patton, 2015). The study sample consisted of 9 families. In one interview both parents participated. One family had two sons (see Table 1). In order to ensure homogeneity of the sample and to illustrate the psychological impact on the families' daily lives, the following inclusion criteria were followed: 1. diagnosis was given at least 12 months before the interview; 2 . all boys were up to 18 years old in order to place emphasis on childhood; 3 . all boys with DMD had reached the stage of loss of their ability to walk; 4. they received appropriate medical and follow-up care; 5 . the boys stayed permanently with the parent(s) who was/were interviewed.

\section{Table 1: Information about interviewed parents $(n=9)$ and their children with DMD ( $n=10)$}

\begin{tabular}{lr}
\hline Father-only & 4 \\
Mother-only & 4 \\
Both parents & 1 \\
Families with one son with DMD & 8 \\
Families with two sons with DMD & 1 \\
Age of son, y & \\
Mean (SD) & $13.2(2.86)$ \\
Median (Range) & $14(9-17)$ \\
\hline
\end{tabular}

DMD: Duchenne Muscular Dystrophy

\section{Data Collection}

Interviews were carried out during the families' visit at a specialized clinic in Northern Greece for clinical examination of their children. The study was approved by the Scientific Committee and the Board of Directors of the University General Hospital of Thessaloniki AHEPA, Greece, and the Ethics Committee of the Democritus University of Thrace, Greece.

The following procedure was employed: The first author, a psychologist who did not work at the clinic and was not involved in the families' psychological care, visited the clinic which was open on 
Mondays. The researcher approached the parents individually and informed them about the aim and procedures of the study. Parents received all related information both verbally and in written form and signed an informed consent document, which provided a description of the research and a statement that they participated voluntarily and they were free to withdraw or to refuse to answer at any time without penalty. Among the parents who were approached by the researcher, one eligible mother declined participation. In two cases of parental couples there was an agreement between spouses as to which parent would be interviewed. In one case an interview was disrupted for a while, as one father wished to talk with his son's physician. All interviews were face-to-face and conducted in a private office at the clinic, so that parents were close to their children and remained calm and focused. Interviews lasted from 30 to 60 minutes approximately. Immediately after the interviews field notes were kept.

\section{Data Analysis}

Data was processed using thematic analysis technique, which is widely used in qualitative research, as it is a flexible research tool that allows the study of rich and complex data. Thematic analysis is considered the most interesting and provoking-at the same time-part in a qualitative research (Kyriazi, 2006).

In the initial stage analysis of collected data began by verbatim transcription of the interview data by the first author. The researchers reviewed the field notes and the transcripts individually multiple times, to obtain an overall sense of the data and extract the main conceptual groups (Patton, 2015) that reflected the parents' experience. A second interview with one participant was deemed necessary and was conducted by phone in order to obtain clarifications.

Once the researchers familiarized themselves with the entire data set, they identified meaningful units, each one corresponding to a word or phrase. Analysis was then focused at a second level of classification in broader categories. Different codes were connected in order to form main thematic categories that reflected a pattern of answers or meanings (Braun \& Clarke, 2006). Through data categorization process and classification we were led to thematic categories with a conceptual definition, allowing the content of the narrations to be translated into findings, which were then interpreted and discussed in qualitative terms (Patton, 2015). Qualitative findings were reviewed in weekly peer debriefing sessions to detect biases and data errors. Further analysis of the data, permitted the grouping into the following five themes:

Parents' psychological adjustment to the condition of the disorder

1.Parents facing constant losses

2. The role of parental responsibility

3.Social isolation and loneliness

4.Alteration in self-perception

5.Sources of empowerment

\section{Results}

\section{Parents Facing Constant Losses}

Parents notice the deterioration of their child's health condition. Doctors confirm the parents' concerns that the symptoms gradually become more generalized and obvious. This realization comes with feelings of sorrow and despair as parents observe the irreversible progression of DMD despite all their efforts: 
INTERNATIONAL JOURNAL OF ACADEMIC RESEARCH IN PSYCHOLOGY

Vol. 6, No. 1, 2019, E-ISSN:2312-1882@ 2019 HRMARS

"... we were here 6 months ago and... his arms were better...now it's out of control...they're worse. Doctors are telling us it's getting worse and worse...meds don't work on us..." (Participant 01)

"After all the problem is his not ours we are fine, we walk, we stand, we eat... We are all wrong about grumbling... We can take care of ourselves, what can the child do?" (Participant 02)

"It's a huge problem...Huge...It affects the family as a whole...and I cannot deal with it (...) There's nothing I can do at this stage." (Participants 06)

\section{The Role of Parental Responsibility}

Furthermore, parents assume full responsibility for the child's caretaking, as his survival depends increasingly on them. Many express their agony as to how will their child survive if one parent passes away. Many participants acknowledge that responsibility and commitment may lead to an overprotective attitude.

"The only thing I care about to stand by him because if he doesn't get better, he can't make it without us... and the girl [sister] should not take over, she will also study, have a family, have a life of her own." (Participants 06)

"I'm overprotective... Yeah I'm scared...This is the change I see in myself. So is his dad...like "If something happens with you... what next?"I wasn't like this at the beginning." (Participant 07)

Parental responsibility is not limited to responding to the needs of care, as parents try to maintain the conditions for the optimal emotional and psychological state of the child. Hence, some assume a more energetic role, in order for the child to participate in all school activities and maintain stable friendships:

"Our goal is to strengthen his self-confidence. He has two very close friends with whom he gets in touch almost daily [...] He has been accepted by his friends and he has been with these kids for 10 years." (Participant 04)

\section{Social Isolation and Loneliness}

Parents are struggling to cope with painful emotions and manage daily care demands. The complexity of their experience is reflected in a deep sense of isolation. Many feel that others do not understand what they are going through. Their decision to carry the burden of their child's care entirely on their own discourages them from seeking help from others, thus enhancing their feelings of loneliness:

"We are not a family like others. We might get up three to four times at night...There are some peculiarities that don't exist in other families..." (Participants 06)

"Rarely will you find somebody who understands you... we didn't want to burden anyone else. The problem is ours and we are going to deal with it." (Participant 05)

Commitment to the child often results in a limited social life for most parents. Many feel that people are not tolerant of diversity. In addition, job opportunities-especially for the mothers-are extremely restricted, due to the demands of care:

"No it was not my choice I was working and I quit my job afterwards... for doctors' appointments and screenings all the time." (Participant 08) 
INTERNATIONAL JOURNAL OF ACADEMIC RESEARCH IN PSYCHOLOGY

Vol. 6, No. 1, 2019, E-ISSN:2312-1882@ 2019 HRMARS

\section{Alteration in Self-Perception}

Parents report internal personal changes resulting from their experience. Some describe that their attitude towards life has changed, as they have started to prioritize and to accept the irreversible nature of the disorder:

"The rest becomes second priority...financial problems and everything else... It's health issues you can't beat so you should see those in a new light..." (Participant 05)

"I've changed as a person in general..how I see things...in a different way...the misery of everyday life, like I don't have a job or I can't afford this and that, I don't care much anymore." (Participant 07)

Some parents mention that they have identified internal coping mechanisms that they were hitherto not aware of. They feel that when it comes to their child they must be strong and that they have no other choice. A mother describes that she feels empowered and capable to deal with reactions from her social context more courageously than at the beginning:

"...now I'm getting out with my child and pay no attention to anyone, I mean I don't look around me, if someone points at me or feels pity for me; courageously...but I wasn't like that before..." (Participant 08)

Some parents mention that as a result of their experiences they have become more tolerant of diversity. They also compare DMD with other disorders or conditions and feel that it would be more difficult if their child suffered from cancerous diseases or if a sudden accident led to disability or death. Denial of symptoms and rationalization of the disorder characteristics are defense mechanisms employed to protect parents from emotional overcharge and anxiety:

"One's child is in sound health then he gets out and never comes back. There are children who've never walked... I see little children in chemo... with masks... we must learn to put up with it." (Participants 06)

\section{Sources of Empowerment}

Parents mention sources that help them feel empowered and capable of holding on. Despite constantly feeling overwhelmed with sadness and despair, they adopt an active attitude and find the inner resources with which to persevere:

"...At the beginning I thought I didn't have the power to cope with all this...Maybe this is what I call defense? I mean that I first need to be strong myself to deal with this situation."

(Participant 07)

Living in the present is a strategy that many parents employ to control emotions deriving from an unpredictable future. For many this is a way of life that involves a greater focus and commitment in their current activities with the child, as well as a tendency to repress emotions associated with disorder prognosis:

"Where do I lean on? I'm standing on my own feet! I live day by day, not making plans for the future.... thank God we are fine today we don't know what will happen tomorrow. The other day we were at hospital...he was in danger...his lungs, with the flu." (Participant 02)

"...live in the present don't think about tomorrow... We live day by day and maybe this is a way not to feel down. When you don't think about it and you keep this image of the child and stand by him, it doesn't affect you emotionally..." (Participant 09) 
INTERNATIONAL JOURNAL OF ACADEMIC RESEARCH IN PSYCHOLOGY

Vol. 6, No. 1, 2019, E-ISSN:2312-1882@ 2019 HRMARS

Parents' efforts are reflected in the normalcy of everyday family life. They evaluate the good mood and emotional state of the child as especially important, a fact that motivates them to keep up their efforts:

"His smile...he'll go out people love him he's assertive, he has his friends I mean he's not a reserved child and what you'll see is a child on a wheelchair living his life each day." (Participant 09)

Reaching out to other families seems to decrease feelings of isolation. Social bonding permits the process of community formation among members who share mutual support and understanding:

"We've met with other parents; we meet afterwards out of the clinic so you see there are more people who experience more or less the same situation." (Participant 02)

A mother describes that her initial perception of a rare disorder has changed through the years, as she meets more and more families with DMD. This seems to strengthen the perception that the family belongs to a broader community, rather than to an unusual category:

"The doctor told me "rare disorder" here I am [at the clinic] meeting newcomers...there are too many. I mean we thought we were the only ones in the world but we're not rare no more" (Participant 06)

However, for some parents it was terrifying to face a more advanced illness stage and as a result they avoided meeting with other families:

"There were parent support groups and there were a lot of discussions... we imagined how

we would be after the years passed...you don't want to believe that though... and the parents' group was of no help at all." (Participant 09)

The support offered by friends and family, either moral, or practical, is acknowledged by all parents as an important source of empowerment that enables them to handle the upcoming adversities.

Finally, parents identify the most effective coping strategies for dealing with challenging issues and give their advice to other parents of children who might have just received a ND diagnosis. Parents describe the process of the diagnosis as overwhelming, followed by a period of mourning, regardless of one's internal resources. They suggest that maintaining hope, companionship in intimate relationships, good doctor-parent alliance and showing perseverance despite emotional pain, may help parents cope with their own anxiety and emotions. The majority of the respondents believe that parents should restrain from expressing distress during interactions with children, protect them from social stigma associated with disability and live in the present:

"...be strong...calm...first of all the right experts, who will inform the couple correctly...You'll be shocked by the information that your child has this...you can't avoid it, no matter how strong you are" (Participant 07)

"Never show sadness in front of the child...help him not to feel different because he isn't...Care for the moment and for the child's positive traits that will help you feel strong."(Participant 09)

\section{Discussion}

Parents in this study experience feelings of sorrow and despair, a finding that is consistent with the results of other research (Abi Daoud et al., 2004; Bostrom et al., 2006; Nereo et al., 2003). However, these findings need to be interpreted with caution, in order to avoid pathologizing a normal range of responses to loss (Epagneul, 2007). The terminal nature of the illness and the parents' impotence to reverse its degenerative progress-while they are healthy themselves-are factors that seem to increase their commitment to the child. 
INTERNATIONAL JOURNAL OF ACADEMIC RESEARCH IN PSYCHOLOGY

Vol. 6, No. 1, 2019, E-ISSN:2312-1882@ 2019 HRMARS

Many parents take care of their children all on their own, which leads to restricted social interactions and high levels of social isolation and loneliness. Glover et al (2018) indicate that some carers choose not to seek support. Predictably, the social and professional life of the families was limited because of the disorder. This finding is consistent with previous research in the literature (Baiardini et al., 2011; Carnevale et al., 2006; Metcalfe et al., 2008). Parental responsibility and commitment to the child are crucial for the majority of the respondents. The parental role is characterized by an overprotective style, as indicated by previous studies (Carnevale et al., 2006; Mah et al., 2008; Tomiak et al., 2007). Épagneul (2007) suggests that parental overinvestment reflects a sense of emergency, which allows parents to minimize their intense feelings of anxiety and guilt.

As reported by other researchers (Dawson \& Kristjanson, 2003; Knafl \& Gilliss, 2002; Tomiak et al., 2007) parents in our study strive to achieve a sense of normalcy in their daily lives with the child. Parents' efforts to be active in their children's lives and to keep providing encouragement were found to continue through the transition to adulthood (Yamaguchi \& Suzuki, 2015). Although Samson et al. (2009) noted that the disorder is gradually incorporated in the family's daily life, this observation is only partially confirmed by our findings. The majority of participants in this study make strong efforts to maintain a sense of normalcy and they manage to maintain a vulnerable balance-by denying unpleasant information and repressing painful emotions.

Many parents identify positive aspects of their experience. They appear to revise their priorities and perspectives to life, as they evaluate their personal coping resources. The ability to identify benefits in a disease-related experience has been associated with positive psychosocial functioning (Peay et al., 2016). Similarly, Webb (2005) found that parents coped in a practical and positive way. Facing a painful reality, parents become activated and stay more focused on the present and their current activities with the child. Normalcy in the family's life is often maintained by the contact with other families and support offered by the close social environment (Bregman, 1980; Magliano et al., 2014). This finding is also consistent with the findings of a recent study exploring the experience of family members who provide social support to their relative with rheumatoid arthritis (Fallatah \& Edge, 2015). Extended family members offered emotional and practical support to caregivers of an affected family member, thus responding to their social support needs. Social support is a factor that enables adaptation (Glover et al., 2018), although some parents are much less likely to seek help than others. Possible barriers to help-seeking may be high levels of commitment and increased feelings of social isolation.

The findings of the present study indicate that contact with other families who experience a similar situation, may comfort some parents by moderating feelings of loneliness. However, careful attention must be paid as social contact appears to have the opposite results for others. This confirms previous findings that either demonstrate the supportive function of groups (Chen \& Clark, 2007; Chen, 2008; Dawson \& Kristjanson, 2003; Gagliardi, 1991a), or suggest that some parents need to distance themselves from the community related to the disorder (Erby et al., 2006; Hodges \& Dibb, 2010).

Support groups often promote solidarity and meaningful bonds among members. However, closer inspection revealed that those participants who were satisfied with their social support network and with the way they were fulfilling their parental role, evaluated parent support groups as of low importance to them. Our results also suggest that some parents experienced contact with others as painful and confusing, mainly because they were confronted with a painful reality of a later stage of the disorder. 


\section{Conclusion}

To conclude, parents in this study place the child in the center of their experience. Their efforts are mainly directed towards the assurance of normalcy in everyday life. On the other hand, the psychological adjustment to the disorder is often related to a process of personal change, which several parents evaluate as a positive dimension of their experience. This process represents the parents' efforts to integrate the management of the disorder into their everyday routines in order to maintain continuity in family life.

This study has some limitations. First, the clinic was operating on a weekly basis, thus making access to the participants a very time-consuming task. A larger sample and more than one interviews with parents could assure a higher level of validity in this research. Second, it is possible that parents who agreed to participate may have been those who had reached a level of acceptance of DMD and were more willing to discuss about it. The effect of the parents' education level and socioeconomic status on their overall adjustment was not investigated.

Future research could identify the effect of DMD to other family members, by exploring their needs and coping strategies, as these issues were not under investigation in the present study.

Healthcare professionals could benefit from the findings of this study, by recognizing the challenges that parents of a child with DMD face. This awareness can encourage parents to express their feelings and address their problems, in a way that can promote their emotional well-being and psychological adjustment to the disorder.

Funding: The authors received no financial support for the research, authorship, and/or publication of this article.

Declaration of Conflicting Interests: The authors declared no potential conflicts of interest with respect to the research, authorship, and/or publication of this article.

Acknowledgements: The authors would like to thank the Director of the 2nd Pediatric Clinic of the University General Hospital of Thessaloniki “AHEPA” (Greece), Dr Maria Hatzistilianou, for supporting the completion of this research study at the 2nd Special Unit of Neuromuscular disorders.

\section{References}

Abi Daoud, M. S., Dooley, J. M., \& Gordon, K. E. (2004). Depression in parents of children with Duchenne muscular dystrophy. Pediatr Neurol, 31(1), 16-19. doi:

10.1016/j.pediatrneurol.2004.01.011Andersson, P. B., \& Rando, T. A. (1999). Neuromuscular disorders of childhood. Curr Opin Pediatr, 11(6), 497-503.

Baiardini, I., Minetti, C., Bonifacino, S., Porcu, A., Klersy, C., Petralia, P., . . Braido, F. (2011). Quality of life in Duchenne muscular dystrophy: the subjective impact on children and parents. J Child Neurol, 26(6), 707-713. doi: 10.1177/0883073810389043

Bendixen, R. M., \& Houtrow, A. (2017). Parental Reflections on the Diagnostic Process for Duchenne Muscular Dystrophy: A Qualitative Study. J Pediatr Health Care, 31(3), 285-292. doi: 10.1177/174239531878947210.1016/j.pedhc.2016.09.002

Berg, L. B. (2001). Qualitative research methods for the social sciences (4th ed.). Boston: Allyn and Bacon.

Boström, Katrin, Ahlström, Gerd, \& Sunvisson, H. (2006). Being the Next of Kin of an Adult Person With Muscular Dystrophy. Clinical Nursing Research, 15(2), 86-104. doi: 
INTERNATIONAL JOURNAL OF ACADEMIC RESEARCH IN PSYCHOLOGY

Vol. 6, No. 1, 2019, E-ISSN:2312-1882@ 2019 HRMARS

$10.1177 / 1054773805285706$

Boyer, F., Drame, M., Morrone, I., \& Novella, J. L. (2006). Factors relating to carer burden for families of persons with muscular dystrophy. J Rehabil Med, 38(5), 309-315. doi: 10.1080/16501970600731578

Braun, Virginia, \& Clarke, Victoria. (2006). Using thematic analysis in psychology. Qualitative Research in Psychology, 3(2), 77-101. doi: http://dx.doi.org/10.1191/1478088706qp063oa

Bregman, A. M. (1980). Living with progressive childhood illness: parental management of neuromuscular disease. Soc Work Health Care, 5(4), 387-408. doi: 10.1300/J010v05n04_05

Carnevale, F. A., Alexander, E., Davis, M., Rennick, J., \& Troini, R. (2006). Daily living with distress and enrichment: the moral experience of families with ventilator-assisted children at home. Pediatrics, 117(1), e48-60. doi: 10.1542/peds.2005-0789

Chen, J. Y., \& Clark, M. J. (2007). Family function in families of children with Duchenne muscular dystrophy. Fam Community Health, 30(4), 296-304. doi: 10.1097/01.FCH.0000290542.10458.f8

Chen, J.-Y. (2008). Mediators Affecting Family Function in Families of Children with Duchenne Muscular Dystrophy. The Kaohsiung Journal of Medical Sciences, 24(10), 514-522. doi: http://dx.doi.org/10.1016/S1607-551X(09)70010-5.

Cipolletta, S., Marchesin, V., \& Benini, F. (2015). Family Functioning as a Constituent Aspect of a Child's Chronic Illness. J Pediatr Nurs, 30(6), 19-28. doi: 10.1016/j.pedn.2015.01.024

Daoud, A. M. S., Dooley, J. M., \& Gordon, K. E. (2004). Depression in parents of children with Duchenne muscular dystrophy. Pediatr Neurol, 31(1), 16-19.

Dawson, S., \& Kristjanson, L. J. (2003). Mapping the journey: family carers' perceptions of issues related to end-stage care of individuals with muscular dystrophy or motor neurone disease. $J$ Palliat Care, 19(1), 36-42.

Eakes, G. G., Burke, M. L., \& Hainsworth, M. A. (1998). Middle-range theory of chronic sorrow. Image J Nurs Sch, 30(2), 179-184.

Emery, A. E. (1998). The muscular dystrophies. Bmj, 317(7164), 991-995.

Emery, A. E. (2002). Muscular dystrophy into the new millennium. Neuromuscular Disorders, 12(4), 343-349. doi: http://dx.doi.org/10.1016/S0960-8966(01)00303-0

Epagneul, Marie-France. (2007). Du bon usage du concept de « deuil de l'enfant idéal » Réflexions sur la pertinence des aides apportées aux parents d'enfant en situation de handicap. Reliance, 26(4), 43-50. doi: 10.3917/reli.026.0043.

Erby, L. H., Rushton, C., \& Geller, G. (2006). "My son is still walking": stages of receptivity to discussions of advance care planning among parents of sons with Duchenne muscular dystrophy. Semin Pediatr Neurol, 13(2), 132-140. doi: 10.1016/j.spen.2006.06.009

Fallatah, Fatmah, \& Edge, D. S. (2015). Social support needs of families: the context of rheumatoid arthritis. Applied Nursing Research, 28(2), 180-185. doi:

https://doi.org/10.1016/j.apnr.2014.10.004.

Gagliardi, B. A. (1991a). The family's experience of living with a child with Duchenne muscular dystrophy. Appl Nurs Res, 4(4), 159-164.

Gagliardi, B. A. (1991b). The impact of Duchenne muscular dystrophy on families. Orthop Nurs, 10(5), 41-49.

Glover, S., Hendron, J., Taylor, B., \& Long, M. (2018). Understanding carer resilience in Duchenne muscular dystrophy: A systematic narrative review. Dev Med Child Neurol, 1742395318789472. doi: 10.1111/dmcn.1397710.1177/1742395318789472 
INTERNATIONAL JOURNAL OF ACADEMIC RESEARCH IN PSYCHOLOGY

Vol. 6, No. 1, 2019, E-ISSN:2312-1882@ 2019 HRMARS

Gravelle, A. M. (1997). Caring for a child with a progressive illness during the complex chronic phase: parents' experience of facing adversity. J Adv Nurs, 25(4), 738-745.

Hatzmann, J., Maurice-Stam, H., Heymans, H. S. A., \& Grootenhuis, M. A. (2009). A predictive model of Health Related Quality of life of parents of chronically ill children: the importance of caredependency of their child and their support system. Health Qual Life Outcomes, 7, 72. doi: 10.1186/1477-7525-7-72

Hodges, L., \& Dibb, B. (2010). Social comparison within self-help groups: views of parents of children with Duchenne muscular dystrophy. J Health Psychol, 15(4), 483-492. doi: 10.1177/1359105309355491

Kedraka, A. (2013). Adult Educators in Greece. Thessaloniki: Publishing House Kyriakidis Brothers s.a. Knafl, K. A., \& Gilliss, C. L. (2002). Families and Chronic Illness: A Synthesis of Current Research. Journal of Family Nursing, 8(3), 178-198. doi: 10.1177/107484070200800302

Kyriazi, N. (2006). (2006). Sociological research - Critical review of methods and techniques. Athens: Greek Scientific Publications.

LaDonna, K. A. (2011). A literature review of studies using qualitative research to explore chronic neuromuscular disease. J Neurosci Nurs, 43(3), 172-182. doi: 10.1097/JNN.0b013e3182135ac9

Magliano, L., Patalano, M., Sagliocchi, A., Scutifero, M., Zaccaro, A., D'Angelo, M. G., . . . Politano, L. (2014). "I have got something positive out of this situation": psychological benefits of caregiving in relatives of young people with muscular dystrophy. J Neurol, 261(1), 188-195. doi: 10.1007/s00415-013-7176-8

Mah, J. K., Thannhauser, J. E., McNeil, D. A., \& Dewey, D. (2008). Being the lifeline: The parent experience of caring for a child with neuromuscular disease on home mechanical ventilation. Neuromuscular Disorders, 18(12), 983-988. doi:

http://dx.doi.org/10.1016/j.nmd.2008.09.001

Metcalfe, A., Coad, J., Plumridge, G. M., Gill, P., \& Farndon, P. (2008). Family communication between children and their parents about inherited genetic conditions: a meta-synthesis of the research. Eur J Hum Genet, 16(10), 1193-1200. doi: 10.1038/ejhg.2008.84

Moraiti, A. (2011). The lived experience of parents raising a child with Duchenne muscular dystrophy. (Doctoral Thesis), National and Capodistrian University of Athens, Athens. Retrieved from https://www.didaktorika.gr/eadd/handle/10442/28653.

Nereo, N. E., Fee, R. J., \& Hinton, V. J. (2003). Parental stress in mothers of boys with duchenne muscular dystrophy. J Pediatr Psychol, 28(7), 473-484.

Patton, M. Q. (2015). Qualitative research \& evaluation methods : integrating theory and practice (4th ed.). Thousand Oaks, CA: Sage Publications

Peay, H. L., Meiser, Bettina, Kinnett, Kathleen, Furlong, Pat, Porter, Kathryn, \& Tibben, A. (2016). Mothers' psychological adaptation to Duchenne/Becker muscular dystrophy. European journal of human genetics : EJHG, 24(5), 633-637. doi: 10.1038/ejhg.2015.189

Poysky, J., \& Kinnett, K. (2009). Facilitating family adjustment to a diagnosis of Duchenne muscular dystrophy: April 24-25, 2008, Miami, Florida. Neuromuscular Disorders, 19(10), 733-738. doi: http://dx.doi.org/10.1016/j.nmd.2009.07.011

Roy, J. (2008). Apres l'annonce d'une maladie chronique évolutive: une autre pratique d'accompagnement. [After the diagnosis of a progressive chronic disease: Another approach to support]. Neuropsychiatrie de l'Enfance et de l'Adolescence, 56(2), 95-99. doi: http://dx.doi.org/10.1016/j.neurenf.2008.01.004 
Saetrang, T., Bjork, I. T., Capjon, H., \& Rasmussen, M. (2019). Parent-child communication and timing of interventions are challenges in the Duchenne muscular dystrophy care. Acta Pædiatrica, 108(3), 535-540. doi: 10.1111/apa.14537

Samson, A., Tomiak, E., Dimillo, J., Lavigne, R., Miles, S., Choquette, M., . . Jacob, P. (2009). The lived experience of hope among parents of a child with Duchenne muscular dystrophy: perceiving the human being beyond the illness. Chronic IIIn, 5(2), 103-114. doi: $10.1177 / 1742395309104343$

Tomiak, E. M., Samson, A., Miles, S. A., Choquette, M. C., Chakraborty, P. K., \& Jacob, P. J. (2007). Gender-specific Differences in the Psychosocial Adjustment of Parents of a Child with Duchenne Muscular Dystrophy (DMD): Two Points of View for a Shared Experience. Qualitative Research Journal, 7( 2), 2-21. doi: 10.3316/QRJ0702002

Webb, C. L. (2005). Parents' perspectives on coping with Duchenne muscular dystrophy. Child Care Health Dev, 31(4), 385-396. doi: 10.1111/j.1365-2214.2005.00518.x

Yamaguchi, M., \& Suzuki, M. (2015). Becoming a back-up carer: parenting sons with Duchenne muscular dystrophy transitioning into adulthood. Neuromuscul Disord, 25(1), 85-93. doi: 10.1016/j.pedhc.2016.09.00210.1016/j.nmd.2014.09.001 